\title{
Influence of resin cement and thermocycling on milled lithium disilicate ceramic microshear bond strength
}

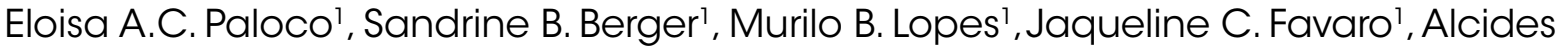 \\ Gonini-Júnior ${ }^{2}$, Allan I. F. Piauilino ${ }^{3}$, Alexandre M. Borba'³ ${ }^{3}$ Ricardo D. Guiraldo' \\ 1. Universidade Pitágoras Unopar, Faculdade de Odontologia, Departamento de Odontologia Restauradora, Londrina, \\ Brasil \\ 2. Universidade Estadual de Londrina, Faculdade de Odontologia, Departamento de Odontologia Restauradora, \\ Londrina, Brasil \\ 3. Universidade de Cuiabá, Faculdade de Odontologia, Departamento de Odontologia, Cuiabá, Brasil
}

\begin{abstract}
The aim of this study was to compare the microshear bond strength of different resin cements to CAD/CAM-created lithium disilicate ceramics after 24 hours and after 1 year (10,000 thermocycles). Forty (40) ceramic bars were subjected to pretreatment comprising airborne abrasion with aluminum oxide particles, etching with 10\% hydrofluoric acid and Monobond $N$ application. Bars were divided into 4 groups ( $n$ =10), based on cement type: light-cured Variolink Esthetic LC (VLC) and dual-cured Variolink $N(V N)$ at two different times: after 24 hours and after 1 year. Silicone molds were used to prepare cement cylinders on a ceramic surface. The set was stored in distilled water at $37^{\circ} \mathrm{C}$, for 24 hours or subjected to 10,000 thermocycles. The molds were removed and microshear bond strength was tested. Data were submitted to two-way
\end{abstract}

analysis of variance and Tukey's test $(\alpha=0.05)$. Based on the comparison between cement values at different aging times ( $p=$ 0.035), VN after 24 hours (27.10 \pm 0.92$)$ and after 1 year (20.62 $\pm 1.25)$ presented significantly higher values than VLC after 24 hours $(14.79 \pm 0.76)$ and after 1 year $(6.61 \pm 0.81)$. Bond strength recorded for both cements after 24 hours (VN: $27.10 \pm$ 0.92 and $V L C: 14.79 \pm 0.76)$ was significantly higher than the one recorded after 1 year (VN: $20.62 \pm 1.25$ and VLC: $6.61 \pm$ 0.81). The thermocycling reduced the values observed for both investigated cements; bond strength was greater for dual-cure resin cement than for light-cured resin cement.

Received: June 2021; Accepted: August 2021.

Keywords: ceramics - strength, sherar - cementation.

\section{Influência do cimento resinoso e da termociclagem na resistência de união à cerâmica de dissilicato de lítio fresada}

\section{RESUMO}

O objetivo nesse estudo foi comparar a resistência de união de diferentes cimentos resinosos à cerâmica de dissilicato de lítio processada por CAD/CAM após 24 horas e após 1 ano (10.000 termociclos). Foram utilizadas 40 barras cerâmicas com tratamento prévio por jateamento com óxido de alumínio, condicionamento com ácido fluorídrico $10 \%$ e aplicação do Monobond N. As barras foram divididas em 4 grupos $(n=10)$ de acordo com o tipo de cimento: fotopolimerizável Variolink Esthetic LC (VLC) e dual Variolink $N(V N)$ em diferentes tempos: após 24 horas e 1 ano. Matrizes de silicone foram usadas para preparar cilindros de cimento na superficie cerâmica. O conjunto foi armazenado em água destilada a $37^{\circ} \mathrm{C}$ por 24 horas ou submetidos protocolo de termociclagem com 10.000 ciclos. As matrizes foram removidas e o teste de microcisalhamento realizado. Os dados foram avaliados por análise de variância a dois fatores e teste de Tukey $(\alpha=0,05)$. Ao comparar os valores dos cimentos em diferentes tempos de envelhecimento $(p=0,035)$, observou-se que VN, após 24 horas $(27,10 \pm 0,92)$ e 1 ano $(20,62 \pm 1,25)$ apresentou valores significativamente superior a VLC após 24 horas $(14,79 \pm 0,76)$ e 1 ano $(6,61 \pm 0,81)$. A resistência para ambos os cimentos após 24 horas (VN: 27,10 \pm 0,92 e VLC: $14,79 \pm 0,76)$ foi significativamente superior que 1 ano (VN: $20,62 \pm 1,25$ e VLC: $6,61 \pm 0,81$ ). A termociclagem promoveu diminuição nos valores de ambos os cimentos estudados e o cimento resinoso dual mostrou maior resistência de união que o cimento resinoso fotopolimerizável..

Palavras-chave: cerâmicas - resistência ao cisalhamento cimentação. 


\section{INTRODUCTION}

Ceramic restorations are widely used in dental treatments ${ }^{1}$. They present thermal expansion coefficient compatible to teeth, biocompatibility, resistance to wear, favorable aesthetic results and clinical longevity ${ }^{2}$. Technological innovations associated with advances in restorative material have improved production methods and mechanical properties of new materials, affecting their use in dental professionals' daily routine ${ }^{3}$.

Lithium disilicate ceramic stands out among these new materials due to its aesthetic effectiveness, mechanical properties, optical characteristics and accuracy. In addition, its manufacturing process involves more convenient production time and lower $\operatorname{cost}^{3}$. This material was developed to extend the indications of glass ceramics beyond the anterior teeth $^{4}$, and is recommended for inlays, onlays, veneers, anterior and posterior crowns, and implantsupported crowns ${ }^{1}$. It can be obtained by heat press technique (IPS e.max Press) based on the lost wax technique ${ }^{4,5}$. In addition, partially pre-crystallized blocks (IPS e.max CAD) have been introduced on the market to enable this material to be used with $\mathrm{CAD} /$ CAM technology ${ }^{1,5}$. Regarding its microstructure, topography, roughness and fractal dimension, milled lithium disilicate ceramics is smoother and more homogeneous, and has greater topographic feature complexity than the material that is used with the pressed technique 5 . Highly aesthetic restorations can be based on prefabricated ceramic blocks, with fewer defects and porosities than restorations based on conventional techniques ${ }^{1,5}$.

Dual or light-cured resin cements are the main materials used for CAD/CAM-created lithium disilicate ceramic cementation ${ }^{6}$. According to the cementation procedure, the internal surface of ceramics is pretreated with hydrofluoric acid (HF) and/or subjected to airborne abrasion with aluminum oxide particles and silane, in order to enable mechanical retention and chemical bonding between cement and ceramics ${ }^{6-9}$.

The success of ceramic restorations is directly related to the cementation process ${ }^{10}$. Although the effectiveness of the bond between the dental surface and resin cements has been extensively investigated, little information is currently available in the literature about the influence of simulated aging time and cement type on the microshear bond strength of milled lithium disilicate ceramics.
Thus, the aim of the current study was to compare the bond strength of two resin cements - dualcured and light-cured - in milled lithium disilicate ceramics, after 24 hours and thermocycling (after 1 -year simulated aging). The null hypotheses tested were: (1) cement type and (2) thermocycling would not influence the microshear bond strength of $\mathrm{CAD} /$ CAM-created lithium disilicate ceramics.

\section{MATERIALS AND METHODS}

A lithium disilicate ceramic block (IPS e.max CAD CAM, Ivoclar Vivadent, Schaan, Liechtenstein) in shade HT A1 was sectioned with diamond disc at low speed (Isomet Diamond Wafering Blades, Buehler Ltd., Lake Bluff, IL, USA) and subjected to crystallization firing process (Programat CS2, Ivoclar Vivadent), according to the manufacturer's recommendations.

Forty ceramic bars $(6.5-\mathrm{mm}$ long $\mathrm{x} 5$-mm wide $\mathrm{x}$ 1 -mm thick) were used. The bars were polished with 400, 100, 1200 and 1500-grit wet silicon carbide abrasive paper for 2 minutes (Norton Abrasivos, Recife, PE, Brazil) and ultrasound-cleaned in distilled water for 5 minutes. Subsequently, they were air abraded with $50-\mu \mathrm{m} \mathrm{Al}_{2} \mathrm{O}_{3}$ particles for 15 seconds at pressure of 2.5 bar (Micro-etcher ERC, Danville Engineering, San Ramon, CA, USA) and ultrasound-cleaned again in distilled water for 5 minutes. Finally, the bars were etched with $10 \%$ hydrofluoric acid for 20 seconds (Dentsply, Petrópolis, RJ, Brazil).

Monobond N (Ivoclar Vivadent Ltda, Barueri, SP, Brazil) was applied on the surfaces of ceramic bars, according to the manufacturer's instructions. Table 1 shows the resin cements used and composition. Four treatment groups $(n=10)$ were determined based on resin cement type: light-cured Variolink Esthetic LC (VLC; Ivoclar Vivadent Ltda, Barueri, SP, Brazil) and dual-cured Variolink N (VN; Ivoclar Vivadent Ltda, Barueri, SP, Brazil); at two different times: after 24 hours and after 1 year $(10,000$ thermocycles, between two water baths, at $5{ }^{\circ} \mathrm{C}$ and $55{ }^{\circ} \mathrm{C}$ with a dwell time of 30 seconds at each temperature extreme, and 2-second interval between immersions $)^{10}$. The following experimental groups were formed: VLC after 24 hours, VN after 24 hours, VLC after 1 year and VN after 1 year.

Two transparent cylindrical molds (Tygon tubing TyG-03, Saint Gobain Performance Plastic, Maime Lakes, FL, USA) - $1 \mathrm{~mm}$ (height) x $0.75 \mathrm{~mm}$ 
Table 1. Resin cements and composition according to the manufacturers.

Resin Cement

Variolink Esthetic LC (Ivoclar

Vivadent Ltda, Barueri, SP, Brasil)

Variolink N (Ivoclar Vivadent Ltda, Barueri, SP, Brasil)
Acronym

VLC

VN
Composition

Urethane dimethacrylate, further methacrylate monomers, ytterbium trifluoride and spheroid mixed oxide, initiators, stabilizers and pigments

Bis-GMA, urethane dimethacrylate, triethylene glycol dimethacrylate, barium glass, ytterbium trifluoride, Ba-Al fluorosilicate glass, spheroid mixed oxide, initiators, stabilizers and pigments

Bis-GMA = bisphenol-A glycidyl methacrylate .

(internal diameter) were placed on the surface of each bar ${ }^{11}$ (Fig. 1A). Resin cements were prepared according to the manufacturer's instructions. A \#5 exploratory probe (HuFriedy, Chicago, IL, USA) was used to apply the resin cements inside the molds. Each resin cement cylinder was light-cured for 20 seconds (Valo - Ultradent Products Inc., South Jordan, UT, USA) at $1,000 \mathrm{~mW} / \mathrm{cm}^{2}$ (Fig. 1B). A ceramic structure (IPS e.max CAD/CAM) was attached to the tip of the light-curing unit $(0.5$ $\mathrm{mm}$ in thickness) to attenuate light transmission and simulate the prosthetic structure. Next, samples were stored in distilled water at $37{ }^{\circ} \mathrm{C}$. After 24 hours or the thermocycling protocol (TC), the molds were carefully cut on opposite sides with the aid of scalpel blade and removed in order to expose two cement cylinders presenting adhesion area of $0.38 \mathrm{~mm}^{2}$ (Fig. 1C). Subsequently, these cylinders were subjected to microshear bond test. To do so, the bars were fixed to a universal testing machine (DL2000; Emic, São José dos Pinhais, PR, Brazil) and load was applied to the base of the cylinders by using steel wire (diameter $0.2 \mathrm{~mm}$ ) at speed of 0.5 $\mathrm{mm} / \mathrm{min}$ until fracture to determine the microshear bond strength ${ }^{12}$ (Fig. 1D). Bond strength values were calculated, and data expressed in MPa. Each group included 10 bars and each bar had two cylinders, providing a total 20 cylinders per group. The mean for the two cylinders of each bar was considered as 1 specimen.

Fractured specimens were analyzed qualitatively under optical microscopy (Olympus Corp., Tokyo, Japan) at 40x magnification. Failure modes were classified as: I - adhesive (resin cement-ceramics interface); II - cohesive (resin cement) and III mixed (combination of adhesive and cohesive fractures in resin cement).

Statistical analysis was performed in Minitab 16

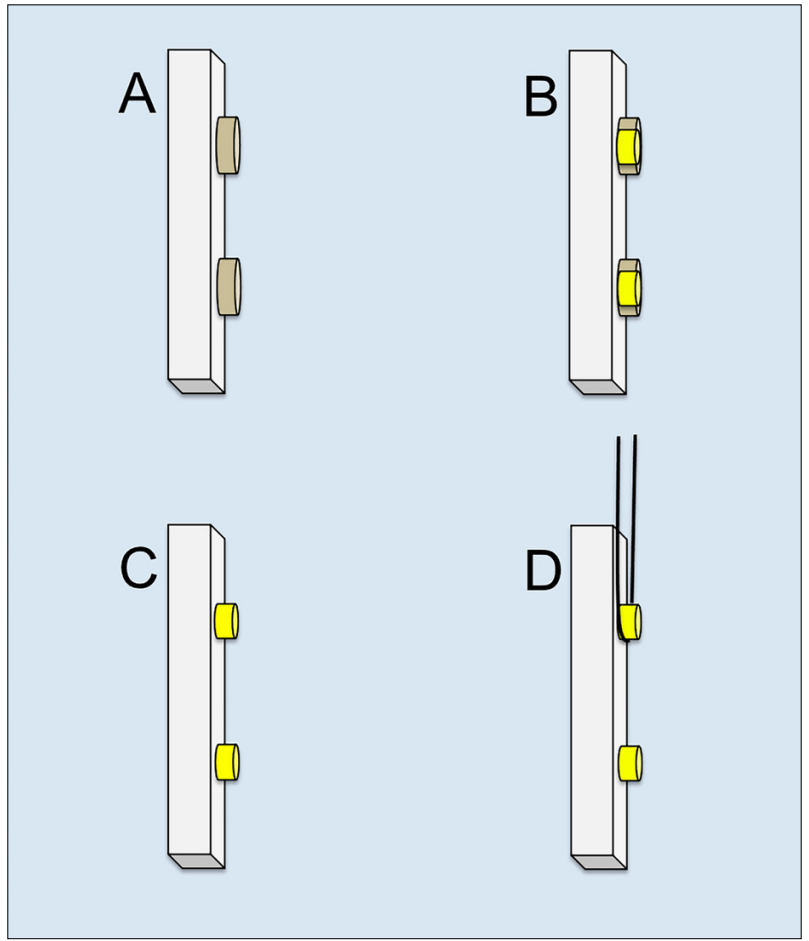

Fig. 1: Specimen preparation - (A) two cylindrical molds positioned on the surface of lithium disilicate ceramic; (B) resin cements filling the internal space of the molds; $(C)$ resin cement cylinders; (D) microshear bond strength test.

software (Minitab, State College, PA, USA). Failure mode results were subjected to nonparametric oneway analysis of variance (ANOVA) and KruskalWallis test $(\alpha=0.05)$. Microshear bond strength results were subjected to Shapiro-Wilk normality test, which was followed by two-way analysis of variance - ANOVA (resin cement $\mathrm{x}$ time) and Tukey's test $(\alpha=0.05)$.

\section{RESULTS}

Mean values of microshear bond strength test $(\mathrm{MPa})$ are listed in Table 2. Comparison of resin cements bond strength values at different simulated aging 


\section{Table 2. Mean microshear bond strength values (MPa) and standard deviation recorded for all groups.}

\begin{tabular}{c|c|c|}
$\begin{array}{c}\text { Resin } \\
\text { Cement }\end{array}$ & \multicolumn{2}{|c}{ Aging time } \\
\hline VN & 24 hours & 1 year \\
\hline VLC & $14.10(0.92) \mathrm{A}, \mathrm{a}$ & $20.62(1.25) \mathrm{A}, \mathrm{b}$ \\
\hline
\end{tabular}

Mean values followed by different uppercase letters in the columns and by lowercase letters on the lines were significantly different from each other, at $p=0.035$ (Tukey's test). Standard deviations are shown in parentheses. VN: Variolink N. VLC: Variolink Esthetic LC.

times showed that the $\mathrm{VN}$ resin cement presented significantly higher resistance values than the VLC resin cement, after 24 hours and 1 year $(p=0.035)$. Based on the comparison between simulated aging times, by taking into consideration the same resin cement type, mean resistance values recorded for both resin cements after 24 hours were significantly higher than the ones recorded at 1-year simulated aging $(\mathrm{p}=0.035)$.

Table 3 lists the failure modes observed for all groups. All groups showed a prevalence of adhesive failures with similarity among the groups $(p=0.725)$ and none of them showed cohesive failure.

Table 3. Failure mode (\%) recorded for all groups.

\begin{tabular}{|c|c|c|c|}
\hline Groups & Adhesive & Cohesive & Mixed \\
\hline VLC 24 hours & $95.0 \mathrm{~A}$ & 0 & $5.0 \mathrm{~A}$ \\
\hline VN 24 hours & $90.0 \mathrm{~A}$ & 0 & $10.0 \mathrm{~A}$ \\
\hline VLC 1 year & $85.0 \mathrm{~A}$ & 0 & $15.0 \mathrm{~A}$ \\
\hline VN 1 year & $85.0 \mathrm{~A}$ & 0 & $15.0 \mathrm{~A}$
\end{tabular}

Mean values followed by same uppercase letters in the columns did not differ significantly at $p=0.725$ (Kruskal-Wallis test). The failure mode was classified as follows: adhesive (ceramic-resin cement interface), cohesive (resin cement) and mixed (involving adhesive and cohesive failures). VN: Variolink N. VLC: Variolink Esthetic LC.

\section{DISCUSSION}

Milled lithium disilicate ceramic is a restorative material. Ceramic blocks of it are manufactured through a pressure casting procedure and supplied in the so-called pre-crystallized blue state. Ceramics in this state present metasilicate and lithium disilicate cores and can be easily milled. After the milling process is complete, restorations are sintered in a ceramic oven and the ceramic is then vitrified ${ }^{1,4}$. Although its composition is similar to that of ceramics obtained by the heat press technique, its production process has great influence on final ceramic features:
$\mathrm{CAD} / \mathrm{CAM}$-created lithium disilicate ceramic has a smoother, more homogeneous appearance and more complex topographic features ${ }^{5}$. Drumond et $a l .{ }^{13}$ report that the ceramic manufacturing technique (Press or CAD/CAM) can influence resin cement bond strength and its conversion degree. This suggests that the manufacturing method of the ceramic used may have influenced the current results, since ceramic surface features may interact with cement to promote adhesion between them ${ }^{5}$.

The cementation procedure plays a significant role in the clinical success of fixed indirect restorations, and depends on the durability and quality of the adhesion among the tooth, the luting agent and the ceramic $^{6,7}$. Mechanical treatments and/or chemical conditioning agents are used to create micromechanical and/or chemical bond to resin cement $^{8,9}$. For this, the standard protocol for adhesive cementation of lithium disilicate ceramics requires blasting with aluminum oxide, conditioning with $\mathrm{HF}$ and silanization the ceramic surface ${ }^{8}$. Blasting comprises ceramic surface abrasion with $50 \mu \mathrm{m}$ aluminum oxide particles to improve mechanical retention $^{8,9}$. Air particle abrasion is a standard procedure performed by dental laboratories before delivering ceramic restorations to dentists ${ }^{8}$. HF removes the glass matrix from the ceramic surface by reacting it to silicon dioxide. This process increases ceramic surface roughness and, consequently, generates micromechanical interlock between resin cement and ceramics ${ }^{6,9}$. Silane coupling agents present bifunctional features. In addition, they have an inorganic group capable of reacting to the silica present on ceramic surface by a condensation reaction, and an organic group that can chemically bond to methacrylate-based resin cements, which enables the chemical bond between ceramic and cement and increases cement wettability ${ }^{6,9}$. Thus, the standard surface treatment protocol applied to lithium disilicate glass ceramic cementation was used in all groups in the present study.

Lower bond strength values have been associated with resin cements presenting lower mechanical properties $^{14,15}$. Resin cements are a polymeric matrix embedded with inorganic fillers. Filler size and content are important factors defining the mechanical behavior of cements. Inorganic fraction increase leads to a decrease in polymerization contraction, and an increase in properties such as elastic modulus, and compressive and flexural 
strength $^{16}$. According to Spazzin et al. ${ }^{15}$, the dualcure resin cement Variolink II presented the best results in flexural strength and elastic modulus, whereas the Variolink Veneer (light-cure) resin cement showed the worst mechanical performance among the tested cements. These findings can be explained by the inorganic filler content observed in the investigated resin cements: Variolink Venner has low filler content, whereas Variolink II resin cement has high filler content ${ }^{15}$. These cements are predecessors to the resin cements used and have similar composition.

The resin cements investigated in the current study were subjected to indirect light-curing, with light transmission through ceramic in order to simulate the clinical procedure. Light transmission through indirect restoration is influenced by its thickness, opacity and shade ${ }^{17}$. In addition, a significant amount of light is lost during polymerization through ceramic due to absorption, dispersion or transmission, which can impair the final polymerization of dual or light-cured resin cements, change their properties and affect the longevity of ceramic restorations ${ }^{18}$. However, extended light-curing time to both light ${ }^{19}$ and dual-cure ${ }^{17}$ resin cements leads to greater polymerization depth, conversion degree, hardness and, therefore, to better mechanical and aesthetic properties ${ }^{17}$. Nonetheless, monomer conversion through dual-cure mode can be greater than that observed through light-cure mode ${ }^{15}$. Therefore, this difference may also be inferred to have influenced the results obtained.

Laboratory studies provide clinically relevant data $^{20}$. To do so, they must simulate different oral environment conditions in order to replicate failure modes similar to those clinically observed ${ }^{20}$, and subject materials to different aging conditions in order to estimate their long-term behavior ${ }^{9,21}$. The TC protocol must be applied to simulate hydrothermal aging in vitro ${ }^{21}$ similar to that of the oral environment ${ }^{20}$. The temperature range adopted herein $\left(5{ }^{\circ} \mathrm{C}\right.$ to $\left.55^{\circ} \mathrm{C}\right)$ is indicated by ISO standards as appropriate ${ }^{20}$, since these variations can result from eating habits, drinking and breathing ${ }^{22}$. Although the frequency of cycles in vivo remains undetermined, some authors ${ }^{21,22}$ assume that these cycles occur between 20 and 50 times a day, and that about 10,000 cycles can represent one-year function in vivo. Temperature changes, along with repetitive stress, are caused by contraction and expansion that occur at the bond interface, since TC has significant negative effect on bond strength. In general, TC seems to decrease resistance values ${ }^{21}$. The present study tested the bond strength of two cements in vitro in the short- and long-term. TC aging had negative effect on bond strength. Samples from groups without TC showed higher values than the aged groups. This unfavorable effect can be attributed to mechanical stresses generated by thermal variations capable of inducing crack propagation along the bond interface ${ }^{22}$ due to differences in thermal expansion coefficient among different materials ${ }^{9,10}$. Findings in the present study are only clinically acceptable (13-30 Mpa) ${ }^{12}$ for dual-cure resin cement after one-year simulated aging, regardless of the microshear bond strength values. According to previous studies ${ }^{14,23}$, dual-cure cements have shown reduced bond strength over time. On the other hand, Peumans et al. ${ }^{10}$ reported increased strength values for dual-cure resin cement Variolink II after 10,000 TC cycles, and such increase remained stable after 40,000 thermocycles. This suggests that resin cement itself plays an important role in the final bond strength between cement and ceramics ${ }^{10}$.

Bond strength tests are simple methods to compare the behavior of different materials in vitro, and different methods have been used for this purpose. Stress distribution in the microshear test can occur more uniformly, since samples do not suffer previous stress caused by sections performed prior to the test, in comparison to the microtensile test. Thus, its use is recommended for ceramic samples ${ }^{2,24}$. Adhesivetype fracture mode is indicative of adhesion between cement and ceramics, and differs from other fracture modes $^{12}$. Adhesive failure was the most prevalent failure type observed in all groups tested in the present study. This is an additional advantage of the microshear test. In addition to not requiring previous section for sample preparation, this test reduces the incidence of cohesive failures ${ }^{24}$. In spite of the choice of the test performed, samples of the light-cured resin cement were excluded as a result of early fractures observed in cement cylinders prior to the test.

The production process can influence the final features of the milled lithium disilicate ceramic, which can interact with the resin cement to promote adhesion. Furthermore, the chemical composition of resin cements can also influence this bond. Depending on the ceramic manufacturing technique 
and the type of cement used, there are differences in the effectiveness of bonding of different resin cements to $\mathrm{CAD} / \mathrm{CAM}$-created lithium disilicate ceramics after thermocycling. This knowledge can be clinically relevant for cementation of milled lithium disilicate ceramic prostheses. One of the limitations of this in vitro study is the isolated use of resin cement, which does not reproduce clinically observed events. The laboratory tests aimed at simulating oral conditions in order to predict clinical bond performances ${ }^{9}$. Restorations in the oral cavity are susceptible to several challenges, such as complex occlusal forces, immersion in saliva and exposure to food and drinks at different temperatures, chemical compositions and $\mathrm{pH}$ values. However, no laboratory test can properly predict the clinical performance of the resin-ceramic bond ${ }^{9}$. Another limitation of this study is the comparison of two cement types (dual- and light-cured) of the same brand. However, these cement types were recommended by the manufacturers of the ceramic

\section{ACKNOWLEDGMENTS}

The authors would like to thank the dentist Fábio Assada, Demomi prosthesis laboratory and the company Biodinâmica Química e Farmacêutica LTDA for their assistance with the methodology.

\section{DECLARATION OF CONFLICTING INTERESTS}

The authors declare no potential conflicts of interest regarding the research, authorship, and/or publication of this article. used in the present study. It would be interesting to test different resin cement types in future research. Studies with long-term water storage and thermocycling are also needed, to evaluate new materials. Thus, based on results in the current study, the null hypotheses were rejected because different bond strength values were observed for milled lithium disilicate glass ceramic subjected to thermocycling and bonded with different cement types.

\section{CONCLUSIONS}

Based on the adopted methodology and materials, and on results observed in the current study, it was concluded that:

1) Thermocycling reduced the values recorded for both cements for the cementation of CAD/CAMcreated lithium disilicate ceramic restorations.

2) The microshear bond strength of the dual-cured resin cement was significantly higher than that of the light-cured resin cement.

\section{FUNDING}

This work was performed with the support of the Coordination for the Improvement of Higher Education Personnel - Brazil (CAPES) - Financing Code 001.

\section{CORRESPONDENCE}

Prof. Dr. Ricardo Danil Guiraldo

Universidade Pitágoras Unopar - UNOPAR

Rua Marselha, 183

86041140 Londrina, PR Brasil

rdguiraldo@gmail.com

\section{REFERENCES}

1. Li RW, Chow TW, Matinlinna JP. Ceramic Dental Biomaterials and CAD/CAM Technology: State of the Art. J Prosthodont Res 2014;58:208-216.

2. Perdigão J, Sezinando A, Muñoz MA, Luque-Martinez IV, et al. Prefabricated veneers - bond strengths and ultramorphological analyses. J Adhes Dent 2014;16:137146.

3. Zarone F, Ferrari M, Mangano FG, Leone R, et al. "Digitally Oriented Materials": Focus on Lithium Disilicate Ceramics. Int J Dent 2016;2016:1-10.

4. Ritzberger C, Apel E, Höland W, Peschke A, et al. Properties and Clinical Application of Three Types of Dental GlassCeramics and Ceramics for CAD-CAM Technologies. Materials 2010;3:3700-3713.

5. Schestatsky R, Zucuni CP, Dapieve KS, Burgo TAL, et al. Microstructure, topography, surface roughness, fractal dimension, internal and marginal adaptation of pressed

and milled lithium-disilicate monolithic restorations. J Prosthodont Res 2019;64:12-19.

6. Prado M, Prochnow C, Marchionatti AME, Baldissara P, et al. Ceramic Surface Treatment with a Single-component Primer: Resin Adhesion to Glass Ceramics. J Adhes Dent 2018;20:99-105.

7. Baratto SS, Spina DR, Gonzaga CC, Cunha LF, et al. Silanated Surface Treatment: Effects on the Bond Strength to Lithium Disilicate Glass-Ceramic. Braz Dent J 2015;26:474-477.

8. Garboza CS, Berger SB, Guiraldo RD, Fugolin AP, et al. Influence of Surface Treatments and Adhesive Systems on Lithium Disilicate Microshear Bond Strength. Braz Dent J 2016;27:458-462.

9. Tian T, Tsoi JK, Matinlinna JP, Burrow MF. Aspects of bonding between resin luting cements and glass ceramic materials. Dent Mater 2014;30:e147-162. 
10. Peumans M, Hikita K, De Munck J, Van Landuyt K, et al. Bond Durability of Composite Luting Agents to Ceramic When Exposed to Long-term Thermocycling. Oper Dent 2007;32:372-379.

11. Shimada Y, Yamaguchi S, Tagami J. Micro-shear bond strength of dual-cured resin cement to glass ceramics. Dent Mater 2002;15:380-389.

12. Sczepanski F, Brunnquell CR, Berger SB, Paloco EA, et al. Evaluation of bond strength of dual resin cements to CAD/ CAM-created lithium disilicate ceramic. Minerva Stomatol 2020;69:153-158.

13. Drumond AC, Paloco EA, Berger SB, González AH, et al. Effect of two processing techniques used to manufacture lithium disilicate ceramics on the degree of conversion and microshear bond strength of resin cement. Acta Odontol Latinoam 2020;33:98-103.

14. Cardenas AM, Siqueira F, Hass V, Malaquias P, et al. Effect of MDP-containing Silane and Adhesive Used Alone or in Combination on the Long-term Bond Strength and Chemical Interaction with Lithium Disilicate Ceramics. J Adhes 2017;19:203-212.

15. Spazzin AO, Guarda GB, Oliveira-Ogliari A, Leal FB, et al. Strengthening of Porcelain Provided by Resin Cements and Flowable Composites. Oper Dent 2016;41:179-188.

16. Tolidis K, Papadogiannis D, Papadogiannis Y, Gerasimou P. Dynamic and static mechanical analysis of resin luting cements. J Mech Behav Biomed Mater 2012;6:1-8.
17. Iriyama NT, Tango RN, Manetta IP, Sinhoreti MA, et al. Effect of light-curing method and indirect veneering materials on the Knoop hardness of a resin cement. Braz Oral Res 2009;23:108-112.

18. Mendonça LM, Ramalho IS, Lima LASN, Pires LA, et al. Influence of the composition and shades of ceramics on light transmission and degree of conversion of dual-cured resin cements. J Appl Oral Sci 2019;27:1-10.

19. Tanoue N, Koishi Y, Matsumura H, Atsuta M. Curing depth of different shades of a photo-activated prosthetic composite material. J Oral Rehabil 2001;28:618-623.

20. Nawafleh N, Hatamleh M, Elshiyab S, Mack F. Lithium Disilicate Restorations Fatigue Testing Parameters: A Systematic Review. J Prosthodont 2016;25:116-126.

21. Özcan M, Bernasconi M. Adhesion to zirconia used for dental restorations: a systematic review and meta-analysis. J Adhes Dent 2015; 17:7-26.

22. Gale MS, Darvell BW. Thermal cycling procedures for laboratory testing of dental restorations. J Dent 1999;27:8999.

23. Siqueira FSF, Campos VS, Wendlinger M, Muso RAC, et al. Effect of Self-Etching Primer Associated to Hydrofluoric acid or Silane on Bonding to Lithium Disilicate. Braz Dent J 2019;30:171-178.

24. Andrade AM, Garcia E, Moura SK, Reis A, et al. Do the microshear test variables affect the bond strength values? Int J Dent 2014;16:323-331. 